\title{
Credibility and legitimacy in policy-driven innovation networks: resource dependencies and expectations in Dutch electric vehicle subsidies
}

\author{
Frank J. van Rijnsoever $\cdot$ Leon Welle $\cdot$ Sjoerd Bakker
}

Published online: 24 November 2013

(C) Springer Science+Business Media New York 2013

\begin{abstract}
The aim of this paper is to empirically examine the influence of credibility on the likelihood to grant consortia of collaborating actors an innovation subsidy. Theorizing from the viewpoint of resource dependence theory and the sociology of expectations, we hypothesize that four types of credibility of influence: scientific credibility, market credibility, expectation track record, and generated social capital. We operate on two levels of analysis, the actor and the consortium. We quantitatively analyze the Dutch electric vehicle subsidy program as case. We develop a model that accurately forecasts which consortia are most likely to receive subsidies. We demonstrate that generated social capital and market credibility positively influence the likelihood of receiving innovation subsidies, while scientific credibility sources and expectation track record have a negative influence. Based on these findings we provide policy recommendations and avenues for further research.
\end{abstract}

Keywords Electric vehicle technology - Expectations - Resource dependence theory $\cdot$ Credibility $\cdot$ Legitimacy $\cdot$ Innovation policy

JEL Classification LO38 - LL620

\footnotetext{
F. J. van Rijnsoever ( $($ )

Innovation Studies, Copernicus Institute of Sustainable Development, Utrecht University, P.O. Box 80115, 3508 TC Utrecht, The Netherlands

e-mail: F.J.vanRijnsoever@uu.nl

L. Welle

Science and Innovation Management, Utrecht University, P.O. Box 80115, 3508 TC Utrecht, The Netherlands

e-mail: leon.welle@alliander.com

S. Bakker

OTB Research Institute, Delft University of Technology, P.O. Box 5030, 2600 GA Delft, The Netherlands

e-mail: S.Bakker-1@tudelft.nl
} 


\section{Introduction}

Over the last decades, efforts to develop a technology that can replace vehicle with an internal combustion engine have increased (Frenken et al. 2004). From 2006 onwards the (battery) electric vehicle has been seen as the most prominent candidate to do so (Bakker 2010). Following these high expectations, the Dutch government introduced an innovation policy to support the development of electric vehicle technology (EVT) and the infrastructure necessary for re-charging. Between 2009 and 2011, 65 million Euros was invested by the government to support a number of test and demonstration projects for electric vehicles. It was anticipated that this investment would result in complementary investment by other parties, totaling to approximately 500 million euros (Ministry of Economic Affairs 2009). With these investments, the government aims to make the Netherlands an international test site for electric vehicles. The Dutch government aims to deploy one million electric vehicles by 2025 . Though promising, according to the ideas about (technological) innovation systems (Edquist 1997; Hekkert et al. 2007), electric mobility can only become successful when different types of institutional actors, ${ }^{1}$ such as firms, societal organizations, knowledge institutes, local authorities, and the national government collaborate in developing this new technology (Ministry of Economic Affairs 2009). Research has indeed shown that consortia in which knowledge from different actor types is combined increase innovative output (Mowery and Rosenberg 1979; Kleinknecht and Verspagen 1990). Therefore the most important goal of the innovation policy was to promote networks of collaborating actors which contributes to development of an innovation system. This innovation system around the technology consists of networks of actors in which resources are exchanged in an institutional environment (Carlsson and Stankiewicz 1991). A well-functioning innovation system crucial for successful innovation, the creation of networks is an important aspect of this (Hekkert et al. 2007).

A prominent approach to explaining collaborations between actors is resource dependence theory (RDT) (Pfeffer and Salancik 2003; Hillman et al. 2009). This perspective argues that actors try to control their environment in order to gain access to crucial resources. Actors can generate crucial resources internally or they can form strategic alliances with other actors to gain access to these resources, which results in the formation of innovation networks (Powell et al. 1996; Ahuja 2000; Schilling and Phelps 2007; Lin et al. 2009). RDT fits the resource oriented definition of innovation systems and can help explaining the development of these innovation networks between actors in the system.

Further, several studies have pointed out the significance of expectations in guiding interests and investments in innovation (Berkhout 2006; Borup et al. 2006; Van Lente and Bakker 2010; Alkemade and Suurs 2012). A technological expectation can be defined as a 'real-time representation of future technological situations and capabilities' (Borup et al. 2006, p. 286). Actors can use positive expectations about an emerging technology to substitute uncertainties about this technology (Brown and Michael 2003). From a resource dependence perspective this means that voicing credible positive expectations about an emerging technology can contribute to legitimizing the allocation of resources for further development of the technology. This legitimacy partly depends on the credibility of the voiced expectations (Berkhout 2006) and characteristics of the actor that voices these

\footnotetext{
${ }^{1}$ In this paper we use the word 'actor' as it is used in innovation system literature. By actor we mean an institutional party in the innovation system that plays a role in developing new innovations, we do not refer to individuals. Subsidized consortia consist of multiple actors, collaborating to develop innovations.
} 
expectations (Deeds et al. 2004; Rao et al. 2008). Voicing credible expectations can thus be seen as a strategic action towards gaining access to crucial resources.

The granting of government subsidies that aim to further develop a technological innovation system through building innovation networks creates a specific opportunity for innovators, where legitimacy is required, to gain access to available resources. Although these subsidy programs make financial resources available to the technological community, such resources are often scarce, and therefore individual members of the technological community usually need to further demonstrate their credibility in order to legitimize them in obtaining a share of this resource. However, no studies exist that study how credibility is related to the likelihood of receiving innovation subsidies.

This paper aims to fill this gap by asking the following research question: "What is the influence of different types of credibility on the likelihood of granting individual actors within consortia an innovation subsidy?" We take the approach that actors increase their legitimacy by possessing different types of credibility, and thereby the likelihood of obtaining innovation subsidy. Drawing on the work by Rao et al. (2008), we hypothesize that four types of credibility influence this likelihood: scientific credibility, market credibility, expectation track record, and social capital generated though the social network. We operate on two levels of analysis, the actor, which are individual firms and knowledge institutes, and the consortium, which consists of collaborating actors.

This paper makes three theoretical contributions. First, Within the RDT, many scholars have researched the formation of inter-organizational relationships or innovation networks between firms (see Hillman et al. 2009 for an overview) and to a lesser extent between science and industry (Van Rijnsoever et al. 2008). However, little empirical attention has been paid to intangible resources in innovation development, such as sources of legitimacy. Deeds et al. (2004) and Rao et al. (2008) form notable exceptions, but their studies are limited to firms operating in a free market. In contrast, we study consortia that consist of different types of actors built around an emerging technology that is supported by the government. This means that the government to a large extent decides which consortia survive.

Second, studies on innovation networks mostly look at the outcome of the network in terms of some measure of innovative performance (Powell et al. 1996; Ahuja 2000; Schilling and Phelps 2007). Others innovation related studies look at scientific productivity (Liberman and Wolf 1998; Lee and Bozeman 2005) and academic career advancement of researchers (Van Rijnsoever et al. 2008), but also at how social networks are used for commercial fundraising by entrepreneurs (Greve and Salaff 2003; Zhang 2010). We add to these studies by looking at how innovation networks influence access to government innovation subsidies.

Third, we combine RDT with the sociology of expectations. Much of the empirical research concerning the role of expectations and their credibility in innovation dynamics relates to effects on entire scientific and technological communities (Bakker et al. 2011; Van Lente and Rip 1998), and there are no studies that specifically focus on the benefits of articulating expectations for individual actors when funds are actually distributed. Combining the sociology of expectations with the RDT gives a micro-foundation to this mesolevel theory. The question of whether expressing expectations by individual actors (or consortia) leads to direct individual benefits is important to the analysis of the role of expectations in processes of innovation. The popular assumption that technology developers, willingly or not, create a "hype" by voicing high expectations, builds partly on the idea that those actors are directly rewarded for raising highly positive expectations (Rip 2006). When actors at a later stage are only rewarded indirectly, through rewards for their 
technological community in general, they are likely to be less keen on promoting the emerging technology.

We quantitatively analyze the Dutch electric vehicle subsidy program as a case study. Using data from a large subsidy scheme in 2010, we develop a model that accurately forecasts which consortia are most likely to receive subsidies. We demonstrate that generated social capital and market credibility positively influence the likelihood of receiving innovation subsidies, while scientific credibility sources and expectation track record have a negative influence.

The outcomes of this research are particularly interesting for industrial organizations and knowledge institutes who wish to gain access to these types of resources. The results provide insights in what strategic actions should be taken in order to gain access to innovation subsidies. The results are also of interest to policy makers. In 2011 the Dutch court of audit (2011) published a report in which the effectiveness and efficiency of the Dutch innovation policy was analyzed. Their research concluded that, while the amount of innovation subsidy more than doubled from $€ 1.8$ billion to $€ 3.7$ billion between 2003 and 2011, the effectiveness and efficiency of Dutch innovation policy could not be determined. Policy makers may use the results of this study to improve the methods by which subsidies are distributed among consortia. This can increase effectiveness of spending and make the distribution of funds more transparent, which provides legitimacy for future innovation policies that are similar.

\section{Theoretical framework}

\subsection{Innovation systems, resources and university-industry collaborations}

According to the innovation systems literature (Carlsson and Stankiewicz 1991; Edquist 1997; Hekkert et al. 2007), innovations are often developed in a social network in which different institutional actors active in the innovation process collaborate through sharing knowledge, experience and resources. Especially for the development of the fundamental knowledge that enables radical innovation it is required that parties from science and industry collaborate together (Sorenson and Fleming 2004). Following Van Rijnsoever et al. (2008) the collaboration between science and industry can be approached from a resource based view (see Barney 1991; Penrose 1959). This perspective argues that an organization can be seen as a bundle of resources and capabilities (Lewin et al. 2004). The resource based view suggests that the various rare and inimitable resources possessed by firms can be translated into a sustainable competitive advantage (Barney 1991). These resources can be both tangible, such as human resources, equipment, buildings, and financial capital, as well as intangible, such as brand equity, in-house knowledge or credibility (Barney 1991; Lewin et al. 2004).

Resource dependence theory is strongly related to the resource based view, but it places more emphasis on the relationship between an organization and its environment (Lewin et al. 2004). According to the RDT organizations are constrained and affected by their environment. Firms cannot generate all the necessary resources internally and therefore have to rely on resources from their external environment. Organizations behave strategically to control critical external resources (Pfeffer and Salancik 2003; Hillman et al. 2009), and can engage in the formation of inter-organizational networks (Ahuja 2000).

Resource dependence theory suggests reasons for both firms and universities engaging in university-industry collaborations. Firms can gain access to highly trained students, high 
quality knowledge, university facilities and faculty, as well as improving their image by collaborating with a prominent academic institution (Fombrun 1996; Santoro and Chakrabarti 2002). Universities primarily engage in industry collaborations for additional research funds, the exposure of students and staff to practical problems, job opportunities for graduates, and access to specific areas of technology (Harman 2001; Nieminen and Kaukonen 2001). Individual scientists can also benefit from collaboration in terms of reputation, career, publications, and other forms of productivity (Siegel et al. 2003; Lee and Bozeman 2005; Van Rijnsoever et al. 2008; Bozeman et al. 2013).

However, it can also be argued that the expected resource benefits of collaboration do not outweigh the investment required; otherwise there would be no need for policies that stimulate university-industry collaboration. For example, university researchers have different aspirations than do firms. Studies have shown that scientists strive for scientific recognition, which is more difficult to gain when collaborating with industry (Carayol 2003; Van Rijnsoever et al. 2008). Firms strive for gaining a competitive advantage (Barney 1991) or to ensure survival (Pfeffer and Salancik 2003). They need to bridge cognitive and cultural barriers in order to apply scientific knowledge (Siegel et al. 2003), which is often problematic. Alongside the time and effort required to maintain network ties (Burt 1999), these are barriers that hamper the formation of science-industry networks. Innovation policy can help to overcome these barriers.

\subsection{The strategy of voicing credible expectations}

The central claim of the sociology of expectations is that positive expectations of an emerging technology can help to stimulate, steer, and coordinate the innovation process (Bakker 2010; Borup et al. 2006; Van Lente 1993). According to Borup et al. (2006, p. 285), expectations can be seen as fundamentally 'generative', providing structure and legitimacy, guiding various activities, attracting interest, and fostering private and public investment. Expectations are most powerful when they are part of a collective repertoire of ideas and statements. In such cases, these expectations cannot be ignored even by those actors that do not share exactly the same ideas; such expectations are then simply part of social reality. This grants certain legitimacy to the technology about which they are expressed, which can lead to both public and private funding. Assessment of the credibility of expectations and of the actor that express them is made continuously (Bakker et al. 2011). This greatly influences the legitimacy of the emerging technology. Trying to create legitimacy for a new technology by expressing expectations can be viewed as a strategic action to gain control of the actors environment. The credibility of the actor expressing the expectations is an important resource if this strategy is to function.

\subsection{Innovation policy}

Innovation policy developed over the past decades with the objective of encouraging and facilitating the generation, application, and diffusion of new ideas (Nooteboom and Stam 2008). Network failures in the innovation system is one rationale for government involvement in technological advance and innovation (Carlsson and Jacobsson 1997; Chaminade and Edquist 2010). These occur when actors interact poorly with their environment, resulting in a lack of collective vision, technological expectation, and coordination of investment. To reduce network failure, Carlsson and Jacobsson (1997) argue that actors should be tied together by means of reciprocal flows of information and knowledge in order to achieve a good connectivity. 
One way of for reducing network failure is subsidizing consortia in which different institutional actors collaborate on R\&D-projects around an emerging technology (Ministry of Economic Affairs 2009). By making the cost-benefit ratio of collaboration more attractive, these subsidies help actors to overcome the aforementioned barriers to collaborate with other actors. In this way subsidies can be used to facilitate knowledge collaboration between science and industry.

The distribution of subsidies can be seen as a two-stage process. First, the choice of technology is made, partly based on voiced expectations (Borup et al. 2006). Once the subsidy program has been established, consortia consisting of different actors, such as firms and knowledge institutes, can obtain subsidies by sending in project proposals. From RDT it is clear that these subsidies are a valuable resource for firms and knowledge institutes alike, while for start-up ventures in a new technological domain these subsidies are even more crucial for survival. Next to this, the subsidized innovation networks can become an important source from which actors acquire other resources (Adler and Kwon 2002).

Funds are often scarce and only a limited number of proposals can receive funding. Those who decide which proposals are rewarded need to justify their decision, since the subsidies are funded with public (e.g. tax-payers) money. In a society where science and innovation become increasingly more accountable to the general public (Gibbons et al. 1994; Hessels and van Lente 2008), making legitimate decisions about funds becomes increasingly important (Van Merkerk and Robinson 2006). Therefore those (usually a committee) that decide about the distribution of public funds need to act as 'legitimacy maximizing' agents.

\subsection{Research model}

In the following paragraphs, we present our research model and formulate our hypotheses. We apply RDT to explain collaborations between actors in consortia and why these actors voice expectations. The sociology of expectations aids us in explaining why policies are formulated. Further, expectations form a hypothetical extra type of credibility of the individual actor or consortium. Legitimacy is used to explain the decision to grant subsidies to actors in a consortium. Legitimacy can be a property of many things such as forms of organization (DiMaggio and Powell 1983; Hannan and Freeman 1989), industry (Deeds et al. 2004), technology (Berkhout 2006) and policy (Nooteboom and Stam 2008). In this paper we refer to the legitimacy of an actor in a consortium to be granted an innovation subsidy. This legitimacy is an intangible resource that comes from the different types of credibility.

\subsubsection{Credibility}

We refer to the independent variables as types of credibility. Credibility is a broad concept with many dimensions that has been studied in many scientific fields and it is especially important when communicating messages (Rieh and Danielson 2007), which is our domain of interest. We are concerned with actor credibility, which is a form of source credibility. This form of credibility has been extensively studied and debated previously (Hovland and Weiss 1951; Sternthal et al. 1978; Pornpitakpan 2004), however, authors rarely define the concept explicitly, referring instead to elements of that concept, commonly trustworthiness, expertise and reliability. For this study we therefore define source credibility as the trustworthiness, expertise and reliability of an actor. Rao et al. (2008) distinguish several 
sources of legitimacy, which we in this paper refer to as types of credibility. ${ }^{2} \mathrm{We}$ focus on two important types of credibility when it comes to developing an emerging technology such as EVT: scientific credibility and market credibility. Further, given their relevance to the innovation process we add expectation track record as third type of credibility. Finally, following RDT and we acknowledge that credibility can also be derived from consortium partners.

Project proposals of actors or consortia that are most likely to fulfill the program goals should have the highest chance of being granted a subsidy. Since it is fundamentally uncertain which projects are most likely to fulfill these goals, decision makers need to rely on indicators that are likely associated with fulfilling program goals. Credibility can confer trust to the governmental decision makers that the projects will become a success and therefore that the money is well-spent. This works in a similar fashion as research councils that distribute research grants among scientists (Rip 1994; Bornmann et al. 2010) and arguably the way banks grant loans to SMEs (Zambaldi et al. 2011). Legitimacy thus partly depends on the credibility of the actors who submit the proposal, and on characteristics of the actor in relation to the goals of the subsidy program. For example, if the goal of the program is to develop scientific knowledge, then an actor might have a larger chance if it has a strong publication track record that demonstrates its scientific credibility. For each type of credibility we argue why it is likely to be important for the success of the innovation process, which is our main motivation for hypothesizing that credibility increases the chance of obtaining a subsidy.

\subsubsection{Actor and consortium level}

Rao et al. (2008) claim that legitimacy has both external and internal sources. Internal sources are the types of credibility an actor controls within an organization. External sources are the types of credibility in an organizational environment on which an actor relies. RDT states that if an actor does not control a critical resource internally, it needs to rely on other agents in the same environment, such as members of a project consortium. Internal credibility is thus found at the actor level, external credibility is located at the consortium level. Many innovation subsidy programs anticipate this by explicitly calling for applications by consortia rather than individual actors. The innovation network thereby has the character of a two-mode network (see Wasserman and Faust 1994), where the first mode is the actor level and the second mode is the consortia in which the actors collaborate. This is also the case for the subsidy program in our current investigation. We are interested in the likelihood of individual actors to be granted a subsidy or not, which is influenced by credibility on both the actor level and the consortium level. If the results would show that most of this likelihood is explained by the actor level, than this would imply that actors need to enhance their own credibility for gaining subsidies. If the consortium level credibility is dominant in explaining the likelihood of receiving subsidies, then the art building the right consortium becomes much more relevant.

\footnotetext{
${ }^{2}$ Rao et al. (2008) define these sources in terms of legitimacy. To avoid confusion with our dependent variable we refer to these sources as credibility. In our opinion the term credibility also better fits the relationship studied here. Further, Rao et al. also distinguish historical and locational legitimacy. However, since the EVT field is new, historical legitimacy is of less importance. It is partially captured by actor age, but older actors are usually from outside the EVT field. Locational legitimacy was considered as possible concept, but the geographic distances in the Netherlands are relatively small and there are no obvious large EVT clusters yet. Therefore it was not included in the model.
} 
Formally, decisions to grant subsidies are not made for specific actors, but rather for the consortia of which these actors are a part. Therefore we expect that the influence of credibility at the consortium level is stronger than the influence of credibility at the actor level. This results in our first hypothesis:

Hypothesis 1 Credibility at the consortium level has a stronger influence on the likelihood of obtaining innovation subsidies than credibility at the actor level.

\subsubsection{Scientific credibility}

In this paper scientific credibility is defined as the scientific trustworthiness, expertise and reliability of an actor or consortium in the domain of the emerging technology. To scientists scientific credibility is a key resource for obtaining funding to conduct new research and to publish results (Latour and Woolgar 1979; Rip 1994). Scientific credibility is traditionally strongest for knowledge institutes. It is an intangible resource that makes this type of actor an attractive consortium partner. For knowledge institutes, participating in a consortium that applies for more 'practical grants' is only attractive if sufficient gains can be made in terms of funding or other resources that can be transformed into scientific credibility (Hessels and van Lente 2008). This is usually the case if fundamental knowledge needs to be developed. For firms it can be attractive to work with knowledge institutes. Including scientific knowledge in the innovation process has shown to be positively associated with innovation (Meeus et al. 2004; Laursen and Salter 2006).

Scientific credibility of actors and consortia is an important source of legitimacy for obtaining innovation subsidy decisions. It demonstrates that applicants are able to work with the latest scientific ideas in the field (Rao et al. 2008), and thus can contribute to developing new cutting-edge technology. Further, it signifies that consortium partners are able to absorb (Cohen and Levinthal 1990) and combine (Kogut and Zander 1992) knowledge from consortium partners or other entities and to translate these into innovations (Laursen and Salter 2006). Therefore we hypothesize:

Hypothesis 2 Scientific credibility is positively related to the likelihood of obtaining innovation subsidies

\subsubsection{Market credibility}

The practical application of knowledge is a specific goal of innovation policy. This means that ideas, concepts, products, processes or other applications need to emerge from scientific knowledge. Market credibility is the commercial trustworthiness, expertise and reliability of an actor or consortium. Having sufficient market knowledge allows estimating consumer demand (Danneels 2002). Partners and consortia that have such familiarity with the targeted market and its technology have a greater probability of success ( $\mathrm{Li}$ and Calantone 1998; Laursen and Salter 2006), and can be expected to be assessed as more credible than those who are not. In the case of an emerging technology, past performance in the market is often limited since the technology is new and therefore the market is immature. Such immature markets can draw two types of commercial actors (see Hannan and Freeman 1989). The first are specialist firms that are almost solely dedicated to the market of the emerging technology. These firms are often new start-ups and therefore relevantly small. They depend for their survival on innovation subsidies. Secondly, there are generalist firms already active in a number of other markets who are looking for new commercial opportunities. These generalists are often older and larger enterprises. 
According to Hannan and Freeman (1989), specialists are usually the first to enter new markets and are initially able to outcompete generalists. Further, since their survival depends on market success, these entrepreneurs are more motivated to take risks in order to innovate successfully (Van Rijnsoever et al. 2012). For these reasons we expect that actors who have specialized in the emerging technology are more likely to receive subsidies than those who have not.

Hypothesis 3 Market credibility is positively related to the likelihood of obtaining innovation subsidies.

\subsubsection{Expectation track record}

As mentioned above, openly voicing positive expectations creates legitimacy for the emerging technology, which can result in government investments such as subsidy programs. The expectation track record of an actor is its past history of openly voicing expectations about the technology. These openly voiced expectations might also contribute to the chances of their being granted a subsidy. By voicing expectations an actor can steer the direction of technological development and policies (Borup et al. 2006; Hekkert et al. 2007). For example, expectations can influence which types of technology are subsidized and which are not. By voicing expectations, actors can steer funds towards their own area of expertise. Openly voicing expectations also contributes to building a reputation. This reputation can cause the actor to be perceived as an expert in the technological domain, and as an enabler who is important in the field.

Hypothesis 4 Expectation track record is positively related to the likelihood of obtaining innovation subsidies.

\subsubsection{Generated social capital}

Social capital can be defined as 'the goodwill that is engendered by the fabric of social relations that can be mobilized to facilitate action' (Adler and Kwon 2002, p. 17). It 'comes about through changes in the relations among persons that facilitate action... it exists in the relations among persons' (Coleman 1988, pp. 100-101). Social capital is extremely important when controlling the organizational environment (Pfeffer and Salancik 2003). Actors can use their social capital to gain direct or indirect access to crucial resources via their network ties (Coleman 1988; Davidsson and Honig 2003). This means they can use these ties to gain access to the types of credibility required to gain subsidies. By visibly tying themselves to a strategic partner, some these intangible resources can be associated with the actor (for example: reputation). By forming project consortia, the partners involved can share credibility and compensate for each other's shortcomings, thereby increasing the chance of obtaining subsidies. Social capital represents outcome of the social processes through which this sharing of credibility takes place. Social capital can be found at the actor level, but the consortium itself also has social capital. Based on social network analysis (Wasserman and Faust 1994) we distinguish two possible attributes that generate the social capital of an agent, the number of network partners and the position of the actor in a network (Coleman 1988). Both are expected to increase legitimacy and thus to positively influence the likelihood being granted a subsidy.

Hypothesis 5 Social capital generated through network partners and network position is positively related to the likelihood of obtaining innovation subsidies. 


\subsubsection{Control variables}

We control for the type of actor: this can be a Small or medium-sized enterprise (SME), large enterprise (LE), or knowledge institute (KI). These are the institutional actor types that are explicitly mentioned in the subsidy program we study, but they are theoretically grounded in innovation systems literature (Edquist 1997) and literature about science industry collaboration (Etzkowitz and Leydesdorff 2000). SMEs are firms with maximal 250 employees, more than 250 employees means that firm is a LE (European Commission 2003). SMEs are usually credited with being more innovative than LEs, while the latter have more resources and experience (Chandy and Tellis 2000). Knowledge institutes are not for profit institutes that conduct fundamental or applied research, such as universities or public research institutes. KIs are assumed to bring in the required scientific knowledge for innovation. The specific program in our study required the presence of at least one SME and one KI in a consortium. This can influence the relationship between the credibility types and the dependent variable. Therefore it is included as control variable.

We also control for the age of the actor, as some credibility types are dependent on age. The effects of age on innovation are ambiguous and mixed (Chandy and Tellis 2000). A popular thought, voiced by a large number of authors is that older firms are less prone to develop innovations than younger firms (Nelson and Winter 1982; Henderson and Clark 1990; Henderson 1993). A common argument is that older firms suffer from inertial forces (Hannan and Freeman 1984). On the other hand, older firms usually have the resources to develop new innovations. Chandy and Tellis (2000) demonstrated that organizational age does not influence the likelihood of introducing radical new innovations. An advantage of older firms is that they have an observable historical track record in developing innovations and the experience to do so. If these firms were successful, then past innovation success can be seen as breeding future success (Rao et al. 2008; Van Rijnsoever et al. 2012). Older firms often have vested interests in the incumbent technology. Not involving some of these older firms might result in a lack of market power capable of replacing the incumbent technology or even in counter strategies (Howells 2002). Decision makers thus have to balance the inertia argument against experiential and counter-strategy arguments when granting subsidies.

\section{Research methods}

\subsection{Empirical case and data collection}

Our empirical study is based on government data involving subsidy grants to proposed projects by consortia of actors. The primary data stems from the HTAS-EVT program (www.htas.nl) and was made available by NL Agency, which is the executive innovation office of the Dutch Ministry of Economic Affairs, Agriculture and Innovation. The goal of the program was to stimulate innovation networks that develop innovations in the field of electric vehicle technology (EVT). This was done by granting innovation subsidies. We choose EVT as a case study since it is an emerging technology that is actively stimulated by the Dutch government, which fits with our theoretical framework. Further, sufficient data was available to empirically test our hypotheses. We stress that results are primarily applicable to the Dutch EVT situation, although other subsidy programs operate in a similar fashion. Consortia consist of at least two actors, of which one is an SME, and the other is a KI or another firm (either LE or SME). Consortia could apply for a subsidy 
between one and five million euros, but also had to dedicate own resources to the project. Criteria for granting were (1) technological newness, (2) the quality of the consortium, (3) sustainable economic perspectives and (4) fit with the core themes of the program. All criteria were of equal importance. Appendix 1 summarizes the translated conditions for obtaining subsidies; the full scheme can be found online in the Dutch "Staatscourant" (Minister of Economic Affairs 2009). A committee ranked the proposals based on their scores on the criteria. Provided that the minimum standards were met, the highest ranked proposals received subsidy. The criteria form the basis of the decision to grant a subsidy. Criterion 2 (quality of the consortium) is most relevant to our research.

The data comprised all consortia that applied for a subsidy for the tender of 2010 (which was the only EVT tender). Our data contains all consortia and actors that applied for a subsidy and information about whether subsidies were granted or not. ${ }^{3}$ In total 23 project consortia consisting of 78 unique actors applied (7 KI, 57 SME, 14 LE). Some actors were involved in multiple consortia, this resulted in repeated observations for an actor. Therefore the dataset contained 118 observations, where each observation represents the participation of an actor in a consortium. The average consortium size was 5.13 partners. Of these 23 consortia 16 were granted a subsidy; corresponding to 76 grants out of 118 observations. These 76 observations consisted of 55 unique partners. Since the total budget was 65 million Euros, the average subsidy was 4.06 million Euros.

To find additional actor characteristics, the data was augmented with information from other sources such as Scopus publication data, LexisNexis newspaper data, actor Web pages and information about the actors from the Dutch Chamber of Commerce. This ensured that the data is objective, non-reactive and therefore more reliable.

\subsection{Measurement}

The decision to grant a subsidy or not to actor $i$ in project consortium $j$ is a dichotomous variable.

Scientific credibility is often expressed through scientific publications (Merton 1968; Baruch and Hall 2004; Lee and Bozeman 2005), it was therefore measured as the number of published scientific articles about EVT by an actor. Publication counts have been used to measure quality of individual researchers (see Gulbrandsen and Smeby 2005; Renault 2006), but also for measuring the quality of research institutes in comparative rankings (Aguillo et al. 2010). Publication counts have shown to be correlated with other measures of scientific quality of institutes, such as research funding (Toutkoushian et al. 2003). Though the measure is by no means perfect (Lehmann et al. 2006), publication counts can be used as a reasonable and straightforward proxy for scientific quality (Anderson et al. 1978). The data source was the scientific database Scopus. On the actor level scientific credibility was measured as the number of scientific articles published by the actor as organization. The publication years ranged between 1993 and 2010. The number of articles ranged between 0 and 21 (median $=0$ ). Since this variable was heavily skewed, its natural logarithm was used. ${ }^{4}$ Theoretically this implies that there are diminishing returns in terms of credibility with each additional article published. In other words, the first 10 articles

\footnotetext{
${ }^{3}$ Unfortunately the data does not provide rankings on the criteria.

4 A value of 1 was added to all observations in order to be able to calculate the natural logarithm for cases with value 0 . After the transformation these values were 0 again, since $\ln (1)=0$.
} 
contribute more than next 10 articles. On the consortium level scientific credibility was measured as the average number of scientific articles published by all consortium partners. ${ }^{5}$

Market credibility relates to the market domain the actor is active in. There is no obvious clear cut measure for this. Since we view market credibility as the degree of specialization (Hannan and Freeman 1989), it was measured as the share of EVT-related products in the total product portfolio of the actor. This approximates how specialized and familiar an actor is with regard to EVT-domain. As data source the websites of the actors were used. If the majority of products in the portfolio of a firm was EVT-related, the firm was regarded a specialist. $20.5 \%$ of the actors were a specialist. All specialists were SMEs. On the actor level the variable is dichotomous; on the consortium level the average of all actors was calculated.

Expectation track record refers to publicly voiced statements about the technology. It was therefore measured as the number of articles that contained positive statements by an actor about EVT in the Dutch newspaper media prior to the tender, the first article appeared in 1990. The data was obtained from the LexisNexis data base in which all Dutch newspapers are archived. The search string was defined as follows: 'name of organization' AND 'elektrisch' (i.e. 'electric' The resulting articles were read, interpreted and inductively coded to determine whether the actor articulated positive expectations about the success of EVT. Articles that were not relevant to EVT were discarded. Positive expectations were measured as future-oriented positive statements about technological progress, expected advantages of EVT in relation to competing technologies, or about progress in rules and regulations around EVT. Content wise, the expectations could be categorized around four themes: environmental advantages, driving performance, (user) convenience, economic advantages and infrastructure. These themes are in line with earlier classifications about car characteristics (Ewing and Sarigöllü 1998; Van Rijnsoever et al. 2009; Lieven et al. 2011; Ziegler 2012; van Rijnsoever et al. 2013) and facilitating conditions for EVT (Morrow et al. 2008; Huétink et al. 2010; Bakker and Trip 2013), which is evidence that the set of expectations identified is theoretically is valid and exhaustive. For each actor the number of positive expectations were added together to form a composite measure for expectations. The number of articles per actor varied between 0 and 21 (median $=0$ ). Although counting newspaper articles is a common measure for expectations in earlier studies (see Bakker 2010; Alkemade and Suurs 2012), again this measure is not perfect. Expectations that were expressed through personal communications are not captured in this fashion. However, since expectations are primarily applied here in the context of gaining public legitimacy, it can be expectations seen as a valid proxy. The measures for actor level and consortium level were calculated in the same manner as for scientific credibility.

Following Coleman (1988) network attributes that lead to social capital were calculated using social network analysis (see Butts 2008; Wasserman and Faust 1994). Actors are linked to each other in project consortia. Together the consortia form a large network consisting of all actors that applied for the subsidy. The ties between actors are thus formed through collaborations in the project consortia. Since actors often participate in multiple projects, consortia are linked to each other. On the actor level the generation of social capital is approximated by the total number of network partners in all projects. This number ranged between 1 and 43 ties (mean $=12.7$ median $=7$ ). The position of the actor in the entire network was calculated using the betweenness centrality measure, which indicates the probability that an actor is on the shortest path in the entire network between

\footnotetext{
5 Other proxies were also tested, such as the sum, the maximum or the natural logarithms of the number of articles published. However, the average number gave the best model results for all types of credibility.
} 
two nodes (Wasserman and Faust 1994; Butts 2008). It thereby reflects the extent to which an actor is involved in communication, and resource flows between actors. Values ranged between 0 and 2,097.8 (mean $=154.9$, median $=0)$. Both measures were calculated using the sna-package (Butts 2012) of the R-program (R Development Core Team 2013). On the consortium level we measured the generation of social capital as the number of ties per actor type per consortium.

All actors were classified by type. Universities and applied research institutes were classified as KI. Following the common EU recommendation (European Commission 2003) companies with $<250$ employees were classified as SMEs, companies with more employees were classified as LE. This information was found in the proposals and augmented with data from the Dutch Chamber of Commerce.

The age of an actor was found on actor websites, Dutch Chamber of Commerce records or (in two instances) through direct contact with the actor. Age ranged from 2 to 167 years ( mean $=26.2$, median $=15)$. Since the distribution of this variable was heavily skewed, the natural logarithm was taken. On the consortium level, the average age of all partners was taken.

Since the consortium level variables are the aggregates of the actor level variables, it is inevitable that they are correlated, with the risk that effects on one level are falsely attributed to the other level or vice versa. To "partial" out the net effects of the actor level variables we followed Greene (1997, p. 246): for scientific credibility, market credibility, expectation track record and age we first regressed the consortium level variables at the actor level variable. We used the resulting unstandardized residuals of these regression models as predictors in the model instead of the original correlated consortium level variables. For social capital we did the same, except for that we regressed the actor level at the consortium level. The result is that the unbiased estimators at the consortium level are retained and that the effects of the actor level variables are made visible. The correlations between the variables are presented in Appendix 2.

\subsection{Analysis}

The decision to grant subsidy to a project $\mathrm{j}$ is not only based on the credibility of the actors and consortia, but also on other criteria. Since we have no information about the other criteria, we do not know to what extent these influence the likelihood of being granted a subsidy. We model the likelihood to be explained by the set of observed variables and an unknown error term. All other factors, including the remaining criteria, but also bounded rational decision making or special circumstances, are encompassed by this error term. This gives the following model:

$$
L_{i j}=\beta_{0 i j}+\beta_{C i} C_{i}+\beta_{C j} C_{j}+\beta_{C V i} C V_{i}+\beta_{C V j} C V_{j}+\varepsilon_{i j}
$$

where $\mathrm{L}$ is likelihood of actor $i$ in project consortium $j$ being granted a subsidy. $C_{i}$ represents the types of credibility of actor i, $C_{j}$ the credibility of the project consortium $j$, $\mathrm{CV}_{\mathrm{i}}$ and $\mathrm{CV}_{\mathrm{j}}$ are sets of control variables at the actor and consortium levels. $\beta_{0 \mathrm{ij}}$ is the model intercept dependent on actor and consortium, the other $\beta$ s represent the regression coefficients for the predictor variables, and $\varepsilon$ is the error term associated with the decision to grant a subsidy to actor $\mathrm{i}$ in consortium $\mathrm{j}$.

Based on this, we tested our hypotheses by fitting a mixed logit model containing a random intercept dependent on the individual actor. This was done using the lme4-package (Bates and Sarkar 2006) of the R-program. The random intercept takes into account the effect of actors who were allowed to participate in multiple project consortia. The model 
was fitted in four steps with being granted a subsidy as dependent variable. The first step contained only the random intercept and the control variables. Step two added credibility variables at the actor level. Step three consists of the control variables and the credibility variables at the consortium level. Finally, step four is called the combined model and contains all variables. As model performance indicator we calculated the McFadden $\mathrm{R}^{2}$ based on the log-likelihoods (McFadden 1974). Further, for each model step the receiver operating characteristic (ROC) curve is calculated to determine the extent to which the model is better than random chance when making predictions (Fawcett 2006). The ROC curve plots the share of correctly predicted cases against the share of falsely predicted cases. The larger the area under the curve, the better the model is at classifying correctly: a value of 0.5 means that the model predicts no better than random chance, a value between 0.7 and 0.8 means an acceptable fit, a value between 0.8 and 0.9 means an excellent fit.

Hypothesis 1 was tested by comparing the model performance between the actor level and consortium level model. This was done by comparing model log-likelihoods using a Chi square test. Hypotheses 2-5 were tested directly in the combined model.

\section{Results}

Prior to discussing our model results, we present a descriptive network graph (Fig. 1) made using the sna-package of the R-program. This provides insights into how the actors are formally related to each other. In the graph actors are represented as nodes, the color of the nodes indicates the type of actor (red $=\mathrm{KI}$, green $=\mathrm{SME}$, blue $=\mathrm{LE}$ ), the size of the node represents predicted probabilities based on the values of the independent variables. The larger the node, the more likely it is that the model predicts that the actor receives a subsidy. The lines represent the ties between the actors. The color of the line indicates whether the relationship was a part of a proposal that was rewarded (black) or not (grey).

The graph shows that KIs have a relatively central place in the network. This is confirmed by an analysis of variance: KIs have on average 17.43 ties, which differs significantly ( $p<0.001$ ) from SMEs and LEs (resp. 7.05; $p<0.001$, and 7.29; $p<0.01$ ). Also, the betweenness centrality measure shows that there are significantly more KIs at the center of the network than other types of actors $(p<0.001)$.

Table 1 displays the results of mixed logit models. The ROC area indicates that the control model predicts only slightly better than random chance. The actor level barely has an acceptable fit (0.70), while the consortium level (0.88) and combined model (0.90) show an excellent fit. Both models are able to predict very accurately the likelihood of granting a subsidy to actor $i$ in consortium $j$. Even though quality of the consortium accounted for only $25 \%$ of the subsidy decision (see Appendix 1), the model predicts far better than that. This can mean two things: consortium quality was weighed more heavily in the decision, or there was correlation between scores on the other criteria and consortium quality (e.g. if consortium quality scores highly, then other criteria were also likely to be higher).

The ROC curves are displayed in Fig. 2. It can be seen that the control model at some point predicts worse than random chance (represented by the diagonal line). The combined model predicts about $67 \%$ of the observations correctly before classifying $9 \%$ of the observations falsely. It can also be seen that the consortium level model drastically outperforms the actor level model. A Chi square test reveals that the consortium level model has a higher model performance compared to the actor level model $\left(\chi^{2}=52.87, d f=1\right.$, $p<0.001)$, and performs equally with the combined model $\left(\chi^{2}=3.27, d f=5, p<0.66\right)$. This supports hypothesis 1 . 


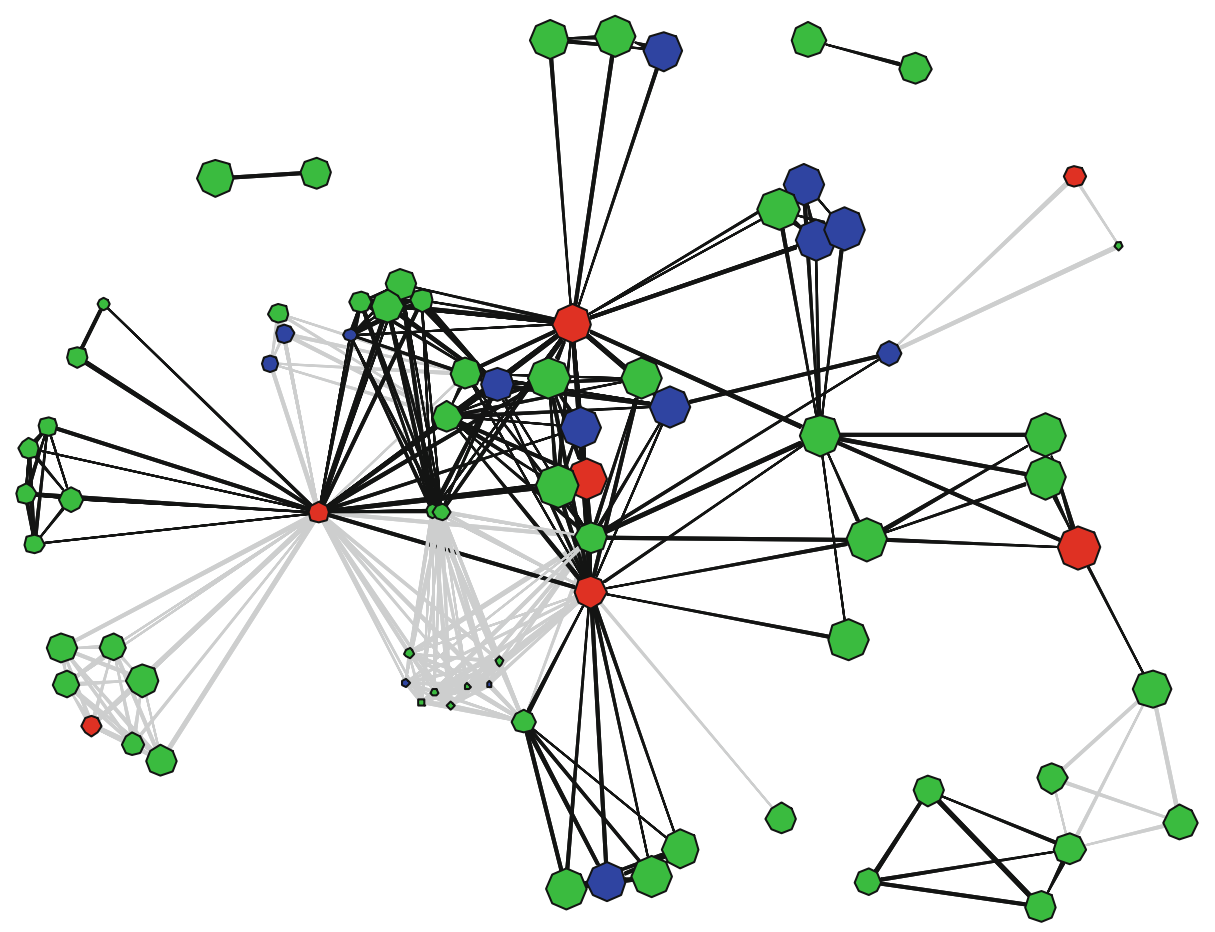

Fig. 1 Social network graph. The color of the nodes indicates the type of actor (red KI, green SME, blue LE), the size of the node represents the predicted probabilities of being granted a subsidy predicted by the mixed logit model. The larger the node, the more probability the model predicts for the actor. The lines represent the ties between the actors. The color of the line indicates whether the relationship was a part of a project that was rewarded (black) or not (grey) (Color figure online)

Model results show that in all models the random intercept equals zero, which means that the variance that originates from participating in multiple proposals is explained by the other fixed variables. The result is that the mixed logit model is collapsed back to the conventional fixed-effects logit model. This has no effect on model estimators or their confidence intervals.

The combined model shows that there are no significant effects by the control variables or the actor level variables. ${ }^{6}$ Scientific credibility on the consortium level is negatively related to the likelihood of receiving a subsidy, which contradicts hypothesis 2. Market credibility of the consortium has a positive influence, supporting hypothesis 3 . Expectation track record at the consortium levels has a negative influence, which contradicts hypothesis 4. The results from generated social capital are mixed: social KI capital positively influences the likelihood of receiving a subsidy, while social SME capital influences this likelihood negatively. Social LE capital has no effect.

The largest contribution to the model comes from social capital generated at the consortium level. The negative effect by scientific credibility is the result of adding social KI capital to the model. This means that given the value of social KI capital, scientific credibility negatively influences the likelihood of receiving subsidies. From a resource

\footnotetext{
${ }^{6}$ We tested extensively for interaction effects between type and credibility at the actor level, but this yielded no significant results.
} 


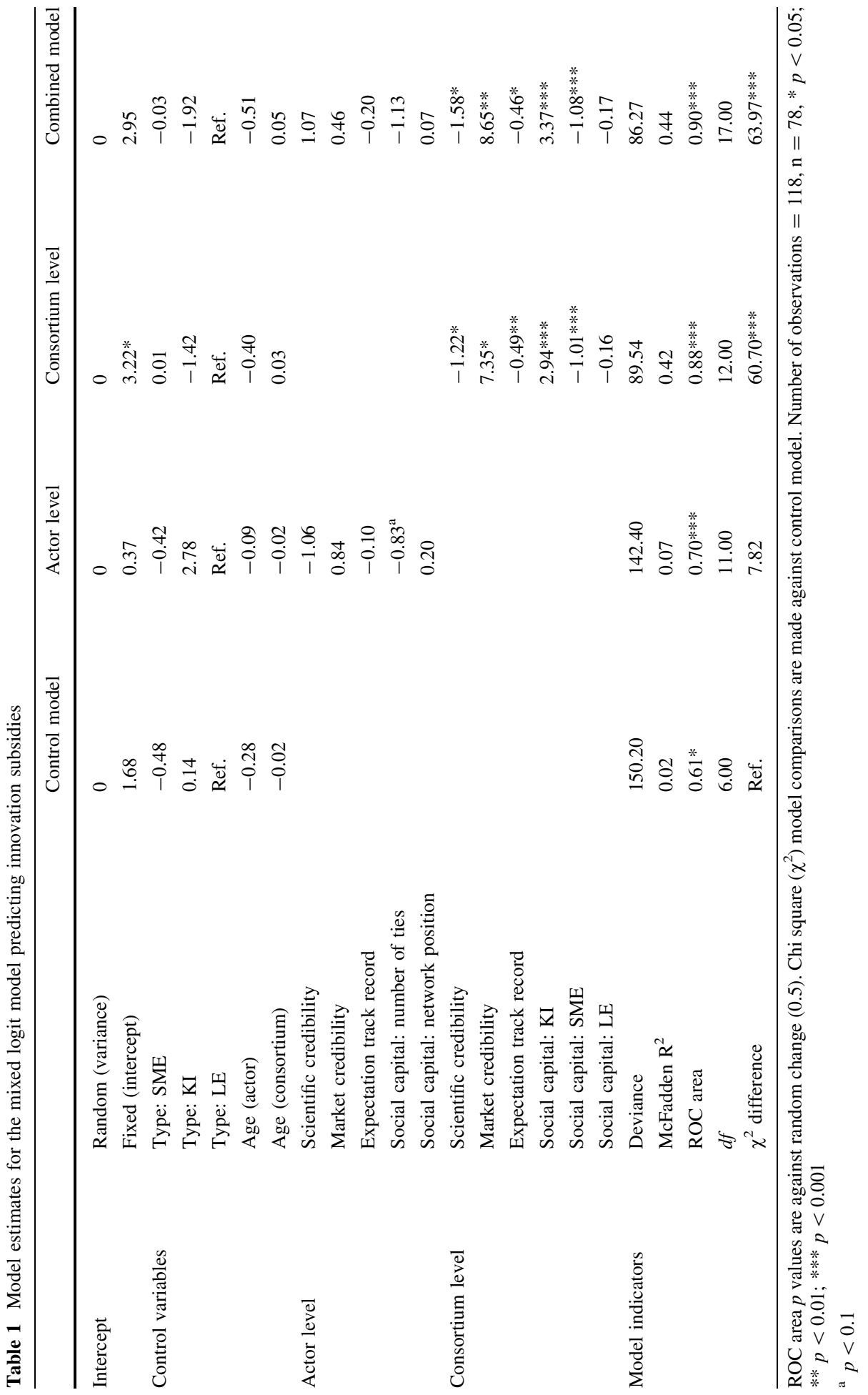




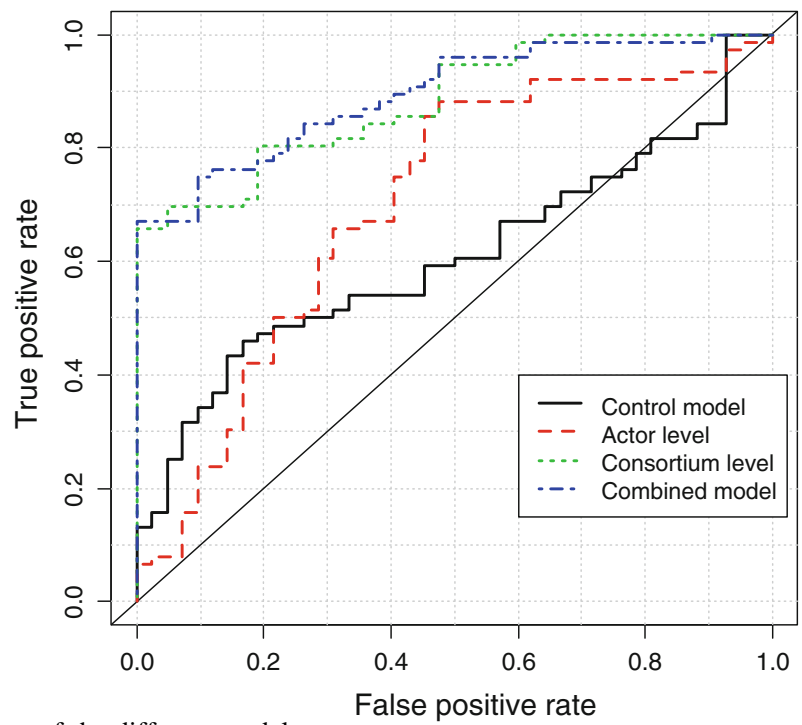

Fig. 2 ROC-curves of the different models

dependence perspective this implies that social capital generated by allying oneself to multiple KI partners is a better resource than the more objectively measured scientific credibility of the consortium. The latter then forms a barrier to obtaining subsidies. The same explanation also applies to the negative effect of consortium on expectation track record. Taking into account generated social capital, expressing expectations publicly appears ineffective and might even jeopardize chances of gaining innovation subsidies. It should be noted that for the latter we only looked at the number of positive expectations expressed and not at the quality of the statements, which might also have had some unobserved influence. However, a possible reason for both negative effects is that the committee making decisions about the subsidies did not look specifically at factual scientific publications and expectation track records, but rather inferred them from the type of actors present in the consortium (for example through reputation). These factual data were not a specific formal criterion on which to evaluate the proposals. Another possible explanation for scientific credibility is that proposals by consortia scoring high on this resource were too scientifically oriented and too far from the market, therefore not meeting the project goals.

Another important resource is market credibility, measured by having a large share of specialist companies dedicated to the emerging technology in the consortium, these are all SMEs. However, having a large number of SMEs in the consortium is also of negative influence. This implies that consortia that consist of multiple KIs and a limited number of specialist SMEs have a greater chance of obtaining subsidies. The SME term in the model thus captures only non-specialized firms. Non-specialized SMEs can be considered redundant and therefore harmful to the chances of obtaining subsidies. Having LEs in the consortium does not contribute anything to the likelihood of getting subsidies, but there is no direct harm either. However, including LEs does lower consortium market credibility 
(the fraction of dedicated SMEs in the consortium). Adding LEs to a consortium lowers this fraction, and thus indirectly influences the likelihood negatively.

\section{Conclusions and discussion}

\subsection{Conclusions}

The aim of this paper was to empirically examine the influence of types of credibility on the likelihood of granting innovation subsidies to individual actors that can help overcoming the barriers for R\&D collaboration between science and industry. This contributes to the build-up of an innovation system around an emerging technology such as EVT.

Our main findings are that consortium level credibility has more influence than actor level credibility. This means that combining intangible resources (credibility) from different actors are key to gain access to financial government resources. In this context actors are thus strongly dependent on each other. Further, in the Dutch EVT case factual achievements by consortia members are less important (or even damaging) for gaining subsidies than the composition of the consortium by type of actor.

\subsection{Theoretical implications}

As far as we are aware, our study is the first to study innovation subsidy decisions in this manner. Theoretically we have made three contributions to the literature. First, we extended resource dependence theory by focusing explicitly on the role of intangible resources in policy driven collaborations between science and industry. Our results demonstrate that the likelihood of an actor receiving an innovation subsidy depends largely on the characteristics of the consortium. High market credibility and having more KIs were of positive influence, while scientific credibility, expectation track record and a larger number of SMEs in the consortium were of negative influence. The negative effects contradicted our theoretical predictions, and are possibly a result of the fact that objective measures of credibility were not required for gaining a subsidy and therefore not taken into consideration. Another possible explanation is that proposals by consortia with high scientific credibility are considered to be too far from the market.

Second, our study is the first that looked at how innovation networks influence gaining access to government innovation subsidies. This dependent variable differs from traditional measures such as innovative performance of firms. The results demonstrate that the social capital generated by network ties is important than credibility from factual achievements. Further, the importance of the consortium level over the actor level shows that combining knowledge and resources from different actors is in this case crucial for being granted a subsidy. This is in line with studies that predict innovation performance (Mowery and Rosenberg 1979; Kleinknecht and Verspagen 1990).

Third, the combination with RDT added micro-foundations to the sociology of expectations, since we explicitly focused on the rewards for individual actors when expressing technological expectations. Expressing expectations provides legitimacy to policy makers so as to initiate subsidy programs that stimulate the development of emerging technologies which are beneficial to the entire technological field. However, in the Dutch EVT case expressing these expectations negatively influenced the chances of actors gaining subsidies. This finding contradicts the idea that articulating positive 
expectations (see Rip 2006) is beneficial to individual actors and thus implies a barrier for publicly promoting an emerging technology.

Another notable finding was the indirect negative influence of having LEs in a consortium. Even though LEs are not always considered to be among the most innovative of firms, they do have resources (such as capital and market power) to develop radical innovations and to enforce breakthroughs against an incumbent regime.

Finally, we empirically tested a model that proved excellent at discriminating between subsidies that were granted and those that were not. It is notable is that we looked only at actor and consortia characteristics; there was no need to look at the content of the project proposals themselves.

\subsection{Limitations and further research}

The main limitation of this study is that we only looked at the Dutch HTAS-EVT case, which contained 118 observations from 78 actors in 23 project consortia. Though this sample is relatively small, it is an entire single population. Our results are primarily limited to this specific subsidy program. However, the types of credibility we theoretically identified all contribute to the development of an emerging technology that would not be developed without government intervention. We expect that similar results are found in other policy programs that aim to facilitate the collaboration between science and industry to promote emerging technologies in a context of increasing accountability of public expenses. Research into similar programs in the Netherlands and other countries is required to further confirm our results.

Due to the number of observations being relatively small we included a limited number of parameters. For example we did consider including the number of EVT patents held by an actor as an additional measure for market credibility, however, we decided against this since the number of patents held in the sample was very low. The model predicted very well, even though the number of parameters was limited. This is partly due to the limited number of observations. Future research studying larger programs should aim to replicate our findings and possibly include additional parameters.

A variable that we did not include in this study was experience in obtaining government subsidies. Past experience implies that capabilities and routines have been learned that allow building and managing these types of consortia and writing credible proposals. They are therefore likely to play a role in the later chances of success for obtaining these types of funds. Related to this is the question of past experience in actually executing these types of projects. Having conducted successful projects in the past increases an actor's credibility. Future research should consider these variables.

Finally, simply because the data was not available we did not study the performance of the consortia that received subsidies. All subsidy decisions are based on expected performance, but we do not know what the actual successes of the projects are and, consequently, how effective the program is. Future research should relate the factors that influence the likelihood of gaining innovation subsidies to actual project performance.

\subsection{Practical implications}

Subsidies can be a useful instrument to help actors overcome the barriers for collaboration and to facilitate the build-up of an innovation system around an emerging technology. To 
legitimize such public expenses it is important that the money is visibly well spent. Ex-post evaluations are one way to determine if expenses were legitimate. However, measuring indicators that are predictive for project success lowers the risk of wasting scarce public funds on projects with no or very low chances of success. Taking into account credibility of consortia in subsidy decisions is one way to achieve this. Further, since governments become increasingly accountable for their expenses, they also need to show (and possibly quantify) the criteria on which the decision to allocate funds is based. This means that such decisions should be transparent. This is in line with reasoning by the Dutch court of audit (2011). Our results lead to four recommendations that can be seen as a follow-up to this. The recommendations therefore contribute to making the subsidy process more legitimate by increasing transparency and contributing to a more effective way of allocating public funds.

Firstly, under current regulations actors need to build their consortia with sufficient KIs and market credibility. Factual achievements such as the number of scientific articles published by consortium partners are currently less important than the type of actor participating. Policy makers that establish subsidy programs can easily increase transparency of the program by specifically adding factual achievements to the criteria for evaluating project proposals. Assuming that consortia with proven track records have a higher probability of innovating successfully, this increases the efficiency of the subsidy program.

Secondly, expressing positive expectations is currently not rewarding for individual actors. It has a negative effect on the creation of the legitimacy of emerging technologies and related subsidy programs. Given the importance of expressing expectations in the innovation process, it is important that actors do not suffer negative consequences from this. Policy makers could take publicly expressed expectations into account as an extra criterion by which to grant subsidies. An additional advantage, as well as creating legitimacy for the program itself, is that it would contribute to creating a positive image of the emerging technology at an early stage. This is important for gaining public acceptance for innovation, which is required in later stages of the innovation process. Policy makers do need to take care that such expectations are measured objectively and also that they do not lead to overly optimistic ideas that eventually lead further to disappointment.

Thirdly, due to their power and resources LEs can play an important role in developing radical innovations and in overthrowing incumbent socio-technical regimes. It can thus be argued that including incumbents in a consortium should be rewarded by policy makers. On the other hand it can also be argued that developing innovations is not in the interest of large incumbent firms, since they have to exchange reliable institutionalized practices with relatively certain rewards for uncertain new ones (Hannan and Freeman 1984). Incumbent LEs might therefore be unwilling to collaborate in an innovation network to develop a new technology. In this case a strategy could be to bring in LEs from a neighboring market to substitute the required resources. A prominent example of this from the last decade is Apple conquering the mobile telephone market, which boosted development of the smart phone. We therefore recommend rewarding the inclusion of LEs in a consortium.

Finally, the model itself can be used as a quick evaluation tool for subsidy programs, to test the extent to which public funds are allocated to the right consortia. Advisory committees and external auditors can check the overall consistency of subsidy decisions, which is especially useful in the case of many applications for subsidy. 


\section{Appendix 1: Literal translation of the criteria for granting subsidies and explanation [see: Staatscourant (Nr. 16803): 1-8]}

\section{Added definitions}

HTAS-EVT-project: An innovation project consisting of experimental development or a combination of experimental development and industrial research that contributes to and fits within the strategic main goals of the HTAS-program as mentioned in Appendix 6.1 and the theme, the specific goals and focus areas as mentioned in Appendix 6.3.

HTAS-EVT-collaboration: a non-legal personality owning a collaboration consisting of two or more, participating members, not in a single group, of which at least one is a SMEentrepreneur and another party is either an entrepreneur or a research organization, executing a HTAS-EVT-project.

Article 6.25

1. Criteria to grant subsidies

(a) Technological novelty or a substantial novel application of an existing technology

(b) Quality of the collaboration at least evident from the complementarity of the participants, the extent to which SMEs are involved and the novelty of the collaboration.

(c) Sustainable economic perspectives of the project results, extensiveness of the possibilities for application of the project results.

(d) The theme of the program and its specific goals and focus areas.

2. When ranking the proposals all criteria are of equal weight.

\section{Explanation of 6.25}

The minister grants subsidies in according to the ranking of the subsidy proposals. HTAS EVT-projects are judged on four equally important criteria. The novelty of the technology or its applications are central to Part A. This also emphasizes the [62] SMEs in the consortium, possibilities for returns on investments and turnover, distinguishable market trends and the position of competitors in the market play a role. One can also consider the follow-up activities that are required to gain a sustainable perspective. If Criterion $\mathrm{C}$ is more often fulfilled this will have a positive impact on employment. The criterion in Part $\mathrm{D}$, relates to the added themes and its specific goals and focus areas described in Appendix 6.3. This is further elaborated upon in Appendix 6.3 under the headings background and theme, HTAS-electric vehicle technology, specific goals, and focus areas.

\footnotetext{
7 Appendices can be found online, these contain technology specific details, but are of no further concern for this study.
} 


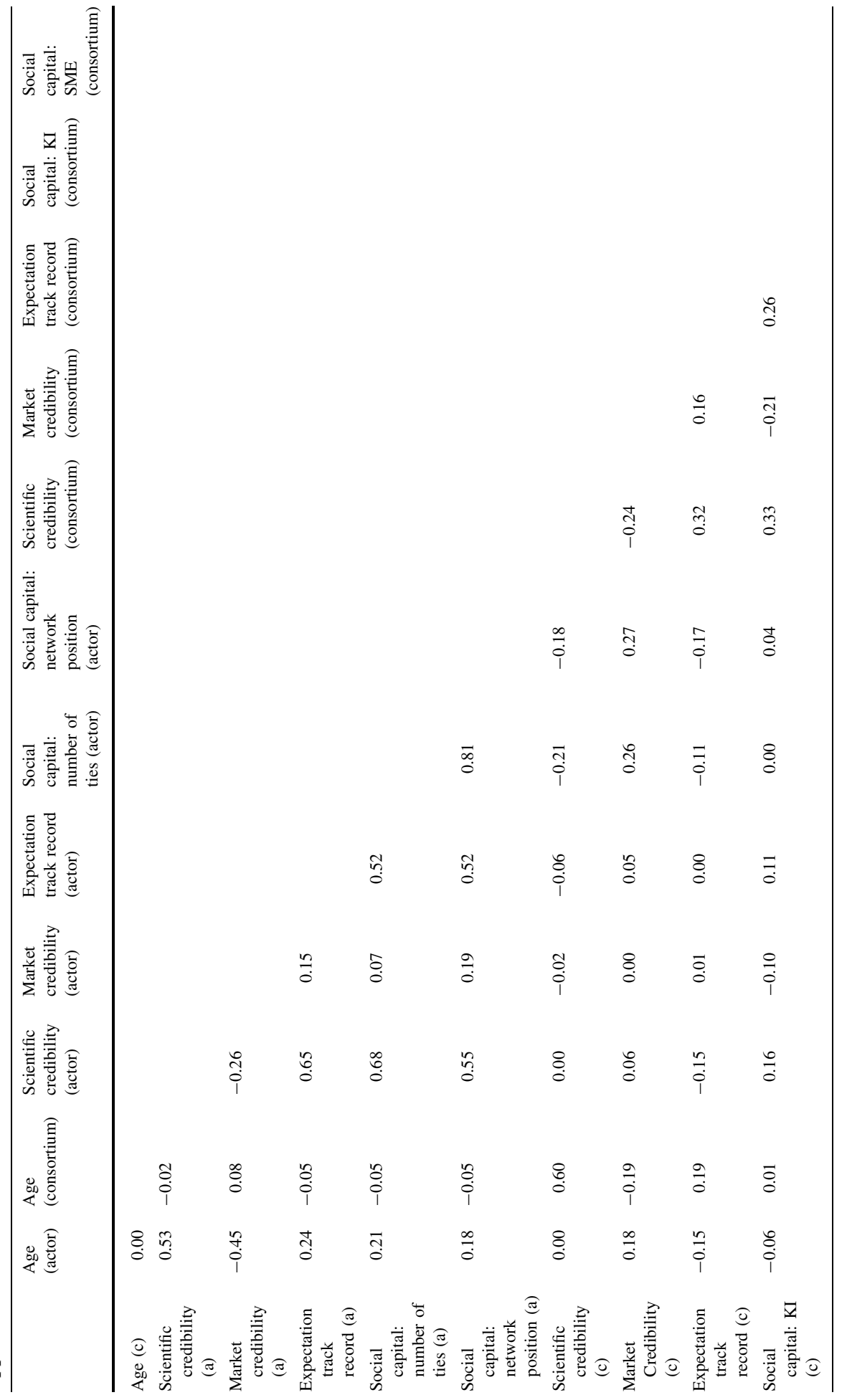




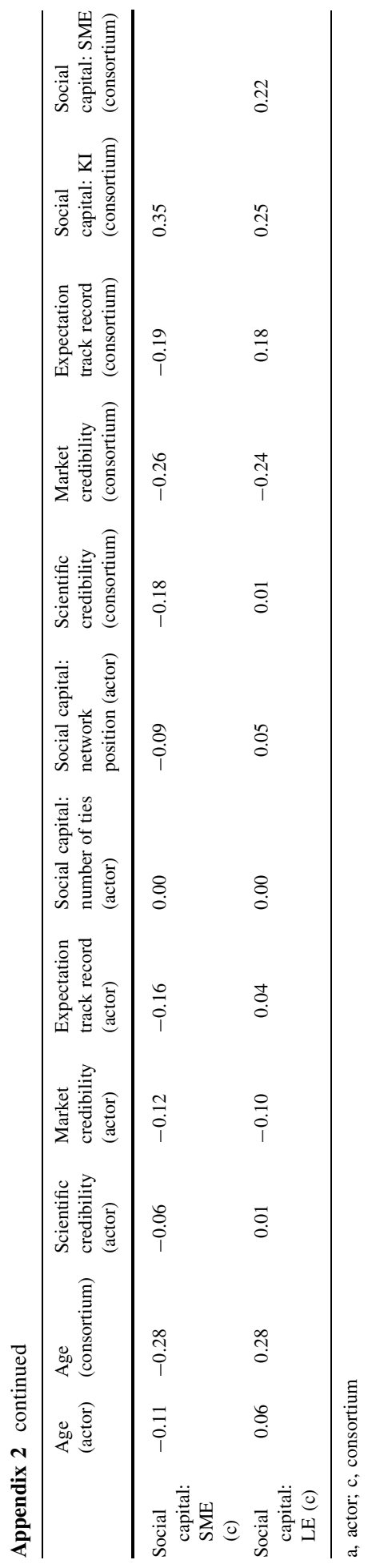




\section{References}

Adler, P. S., \& Kwon, S.-W. (2002). Social capital: Prospects for a new concept. The Academy of Management Review, 27, 17-40.

Aguillo, I. F., Bar-Ilan, J., Levene, M., \& Ortega, J. L. (2010). Comparing university rankings. Scientometrics, 85, 243-256.

Ahuja, G. (2000). Collaboration networks, structural holes, and innovation: A longitudinal study. Administrative Science Quarterly, 45, 425-455.

Alkemade, F., \& Suurs, R. A. A. (2012). Patterns of expectations for emerging sustainable technologies. Technological Forecasting and Social Change, 79, 448-456.

Anderson, R. C., Narin, F., \& McAllister, P. (1978). Publication ratings versus peer ratings of universities. Journal of the American Society for Information Science, 29, 91-103.

Bakker, S. (2010). The car industry and the blow-out of the hydrogen hype. Energy Policy, 38, 6540-6544.

Bakker, S., \& Trip, J. J. (2013). Policy options to support the adoption of electric vehicles in the urban environment. Transportation Research Part D: Transport and Environment, 25, 18-23.

Bakker, S., Van Lente, H., \& Meeus, M. T. H. (2011). Arenas of expectations for hydrogen technologies. Technological Forecasting and Social Change, 78, 152-162.

Barney, J. (1991). Firm resources and sustained competitive advantage. Journal of Management, 17, 99-120.

Baruch, Y., \& Hall, D. T. (2004). The academic career: A model for future careers in other sectors? Journal of Vocational Behavior, 64, 241-262.

Bates, D. M., \& Sarkar, D. (2006). The lme4 library. http://lib.stat.cmu.edu/R/CRAN.

Berkhout, F. (2006). Normative expectations in systems innovation. Technology Analysis and Strategic Management, 18, 299-311.

Bornmann, L., Leydesdorff, L., \& Van den Besselaar, P. (2010). A meta-evaluation of scientific research proposals: Different ways of comparing rejected to awarded applications. Journal of Informetrics, 4, 211-220.

Borup, M., Brown, N., Konrad, K., \& Van Lente, H. (2006). The sociology of expectations in science and technology. Technology Analysis and Strategic Management, 18, 285-298.

Bozeman, B., Fay, D., \& Slade, C. (2013). Research collaboration in universities and academic entrepreneurship: The-state-of-the-art. The Journal of Technology Transfer, 38, 1-67.

Brown, N., \& Michael, M. (2003). A sociology of expectations: Retrospecting prospects and prospecting retrospects. Technology Analysis and Strategic Management, 15, 3-18.

Burt, R. S. (1999). The social capital of opinion leaders. Annals of the American Academy of Political and Social Science, 566, 37-54.

Butts, C. T. (2008). Social network analysis with sna. Journal of Statistical Software, 24, 1-51.

Butts, C. T. (2012). Tools for social network analysis. R package version 2. http://stat.ethz.ch/CRAN/web/ packages/sna.

Carayol, N. (2003). Objectives, agreements and matching in science-industry collaborations: Reassembling the pieces of the puzzle. Research Policy, 32, 887-908.

Carlsson, B., \& Jacobsson, S. (1997). Diversity creation and technological systems: A technology policy perspective. In C. Edquist (Ed.), Systems of innovation: Technologies, institutions and organizations. London: Pinter Publishers.

Carlsson, B., \& Stankiewicz, R. (1991). On the nature, function and composition of technological systems. Journal of Evolutionary Economics, 1, 93-118.

Chaminade, C., \& Edquist, C. (2010). Rationales for public policy intervention in the innovation process: A systems of innovation approach. In R. Smits, S. Kuhlmann, \& P. Shapira (Eds.), The theory and practice of innovation policy: An international research handbook. Cheltenham: Edward Elgar Publishers.

Chandy, R. K., \& Tellis, G. J. (2000). The incumbent's curse? Incumbency, size, and radical product innovation. The Journal of Marketing, 64, 1-17.

Cohen, W. M., \& Levinthal, D. A. (1990). Absorptive capacity: A new perspective on learning and innovation. Administrative Science Quarterly, 35, 128-152.

Coleman, J. S. (1988). Social capital in the creation of human capital. American Journal of Sociology, 94, S95-S120.

Commission, European. (2003). COMMISSION RECOMMENDATION of 6 May 2003 concerning the definition of micro, small and medium-sized enterprises. Official Journal of the European Union, 124, $36-41$.

Danneels, E. (2002). The dynamics of product innovation and firm competences. Strategic Management Journal, 23, 1095-1121. 
Davidsson, P., \& Honig, B. (2003). The role of social and human capital among nascent entrepreneurs. Journal of Business Venturing, 18, 301-331.

Deeds, D. L., Mang, P. Y., \& Frandsen, M. L. (2004). The influence of firms' and industries' legitimacy on the flow of capital into high-technology ventures. Strategic Organization, 2, 9-34.

DiMaggio, P. J., \& Powell, W. W. (1983). The Iron cage revisited: Institutional isomorphism and collective rationality in organizational fields. American Sociological Review, 48, 147-160.

Dutch Court of Audit. (2011). Innovatiebeleid (Innovation Policy). The Hague: Algemene Rekenkamer. Retrieved from http://www.rekenkamer.nl/Publicaties/Onderzoeksrapporten/Introducties/2011/09/ Innovatiebeleid.

Edquist, C. (1997). Systems of innovation approaches-Their emergence and characteristics. In C. Edquist (Ed.), Systems of innovation. London: Pinter.

Etzkowitz, H., \& Leydesdorff, L. (2000). The dynamics of innovation: From National Systems and "Mode 2 " to a Triple Helix of university-industry-government relations. Research Policy, 29, 109-123.

Ewing, G. O., \& Sarigöllü, E. (1998). Car fuel-type choice under travel demand management and economic incentives. Transportation Research Part D: Transport and Environment, 3, 429-444.

Fawcett, T. (2006). An introduction to ROC analysis. Pattern Recognition Letters, 27, 861-874.

Fombrun, C. (1996). Reputation: Realizing value from the corporate image. Boston: Harvard Business School Press.

Frenken, K., Hekkert, M., \& Godfroij, P. (2004). R\&D portfolios in environmentally friendly automotive propulsion: Variety, competition and policy implications. Technological Forecasting and Social Change, 71, 485-507.

Gibbons, M., Limoges, C., Nowotny, H., Schawartzman, S., Scott, P., \& Trow, M. (1994). The new production of knowledge: The dynamics of science and research in contemporary societies. London: Sage.

Greene, W. H. (1997). Econometic analysis (3rd ed.). Upper Saddle River, NJ: Prentice-Hall.

Greve, A., \& Salaff, J. W. (2003). Social networks and entrepreneurship. Entrepreneurship theory and practice, 28, 1-22.

Gulbrandsen, M., \& Smeby, J.-C. (2005). Industry funding and university professors' research performance. Research Policy, 34, 932-950.

Hannan, M. T., \& Freeman, J. (1984). Structural inertia and organisational change. American Sociological Review, 49, 149-164.

Hannan, M. T., \& Freeman, J. (1989). Organizational ecology. Cambridge, MA: Harvard University Press.

Harman, G. (2001). University-industry research partnerships in Australia: Extent, benefits and risks. Higher Education Research \& Development, 20, 245-264.

Hekkert, M. P., Suurs, R. A. A., Negro, S. O., Kuhlmann, S., \& Smits, R. E. H. M. (2007). Functions of innovation systems: A new approach for analysing technological change. Technological Forecasting and Social Change, 74, 413-432.

Henderson, R. M. (1993). Underinvestment and incompetence as responses to radical innovation: Evidence from the photolithographic alignment equipment industry. The Rand Journal of Economics, 24, $248-270$.

Henderson, R. M., \& Clark, K. B. (1990). Architectural innovation-the reconfiguration of existing product technologies and the failure of established firms. Administrative Science Quarterly, 35, 9-30.

Hessels, L. K., \& van Lente, H. (2008). Re-thinking new knowledge production: A literature review and a research agenda. Research Policy, 37, 740-760.

Hillman, A. J., Withers, M. C., \& Collins, B. J. (2009). Resource dependence theory: A review. Journal of Management, 35, 1404-1427.

Hovland, C. I., \& Weiss, W. (1951). The influence of source credibility on communication effectiveness. Public Opinion Quarterly, 15, 635-650.

Howells, J. (2002). The response of old technology incumbents to technological competition-Does the sailing ship effect exist? Journal of Management Studies, 39, 887-906.

Huétink, F. J., der Vooren, A., \& van Alkemade, F. (2010). Initial infrastructure development strategies for the transition to sustainable mobility. Technological Forecasting and Social Change, 77, 1270-1281.

Kleinknecht, A., \& Verspagen, B. (1990). Demand and innovation: Schmookler re-examined. Research Policy, 19, 387-394.

Kogut, B., \& Zander, U. (1992). Knowledge of the firm, combinative capabilities, and the replication of technology. Organization Science, 3, 383-397.

Latour, B., \& Woolgar, S. (1979). Laboratory life: The construction of scientific facts. London: Sage.

Laursen, K., \& Salter, A. (2006). Open for innovation: The role of openness in explaining innovation performance among UK manufacturing firms. Strategic Management Journal, 27, 131-150. 
Lee, S., \& Bozeman, B. (2005). The impact of research collaboration on scientific productivity. Social Studies of Science, 35, 673-702.

Lehmann, S., Jackson, A. D., \& Lautrup, B. E. (2006). Measures for measures. Nature, 444, 1003-1004.

Lewin, A. Y., Weigelt, C. B., \& Emery, J. D. (2004). Adaption and selection in strategy and change: Perspectives on strategic change in organizations. In M. S. Poole \& A. H. Van de Ven (Eds.), Handbook of organizational change and innovation. Oxford: Oxford University Press.

Li, T., \& Calantone, R. J. (1998). The impact of market knowledge competence on new product advantage: Conceptualization and empirical examination. The Journal of Marketing, 62, 13-29.

Liberman, S., \& Wolf, K. B. (1998). Bonding number in scientific disciplines. Social Networks, 20, 239-246.

Lieven, T., Mühlmeier, S., Henkel, S., \& Waller, J. F. (2011). Who will buy electric cars? An empirical study in Germany. Transportation Research Part D: Transport and Environment, 16, 236-243.

Lin, Z., Yang, H., \& Arya, B. (2009). Alliance partners and firm performance: Resource complementarity and status association. Strategic Management Journal, 30, 921-940.

McFadden, D. (1974). Conditional logit analysis of qualitative choice behavior. In P. Zarembka (Ed.), Frontiers in economics (pp. 105-142). New York: Academic Press.

Meeus, M. T. H., Oerlemans, L. A. G., \& Hage, J. (2004). Industry-public knowledge infrastructure interaction: Intra- and Inter-organizational explanations of interactive learning. Industry and Innovation, 11, 327-352.

Merton, R. K. (1968). The Matthew effect in science. Science, 159, 56-63.

Minister of Economic Affairs. (2009). Regeling van de Minister van Economische Zaken van 30 oktober 2009, nr. WJZ/9166533, tot wijziging van de Subsidieregeling sterktes in innovatie. Staatscourant 1-8.

Ministry of Economic Affairs. (2009). Mobiliteitsbeleid (Mobility Policy).

Morrow, K., Karner, D., \& Francfort, J. (2008). Plug-in hybrid electric vehicle charging infrastructure review. US Department of Energy-Vehicle Technologies Program.

Mowery, D., \& Rosenberg, N. (1979). The influence of market demand upon innovation: A critical review of some recent empirical studies. Research Policy, 8, 102-153.

Nelson, R. R., \& Winter, S. G. (1982). An evolutionary theory of economic change. Cambridge, MA: The Belknap of Harvard University Press.

Nieminen, M., Kaukonen, E. (2001). Universities and R\&D networking an a knowledge-based economy. Sitra Reports.

Nooteboom, B., \& Stam, E. (2008). Micro-foundations of innovation policy. Amsterdam: WRR, Amsterdam University Press.

Penrose, E. T. (1959). The theory of the growth of the firm. White Plains, NY: M. E. Sharpe.

Pfeffer, J., \& Salancik, G. (2003). The external control of organizations: A resource dependence perspective. Palo Alto: Stanford Business Books.

Pornpitakpan, C. (2004). The persuasiveness of source credibility: A critical review of five decades' evidence. Journal of Applied Social Psychology, 34, 243-281.

Powell, W. W., Koput, K. W., \& Smith-Doerr, L. (1996). Interorganizational collaboration and the locus of innovation: Networks of learning in biotechnology. Administrative Science Quarterly, 41, 116-145.

R Development Core Team. (2013). R: A language and environment for statistical computing. www.Rproject.org.

Rao, R. S., Chandy, R. K., \& Prabhu, J. C. (2008). The fruits of legitimacy: Why some new ventures gain more from innovation than others. Journal of Marketing, 72, 58-75.

Renault, C. S. (2006). Academic capitalism and university incentives for faculty entrepreneurship. The Journal of Technology Transfer, 31, 227-239.

Rieh, S. Y., \& Danielson, D. R. (2007). Credibility: A multidisciplinary framework. In B. Cronin (Ed.), Annual review of information science and technology (pp. 307-364). Medford, NJ: Information Today.

Rip, A. (1994). The republic of science in the 1990s. Higher Education, 28, 3-23.

Rip, A. (2006). Folk theories of nanotechnologists. Science as Culture, 15, 349-365.

Santoro, M. D., \& Chakrabarti, A. K. (2002). Firm size and technology centrality in industry-university interactions. Research Policy, 31, 1163-1180.

Schilling, M. A., \& Phelps, C. C. (2007). Interfirm collaboration networks: The impact of large-scale network structure on firm innovation. Management Science, 53, 1113-1126.

Siegel, D. S., Waldman, D. A., Atwater, L. E., \& Link, A. N. (2003). Commercial knowledge transfers from universities to firms: Improving the effectiveness of university-industry collaboration. The Journal of High Technology Management Research, 14, 111-133.

Sorenson, O., \& Fleming, L. (2004). Science and the diffusion of knowledge. Research Policy, 33, 1615-1634. 
Sternthal, B., Ruby, D., \& Leavitt, C. (1978). The persuasive effect of source credibility: Tests of cognitive response. Journal of Consumer Research, 4, 252-260.

Toutkoushian, R. K., Porter, S. R., Danielson, C., \& Hollis, P. R. (2003). Using publications counts to measure an institution's research productivity. Research in Higher Education, 44, 121-148.

Van Lente, H. (1993). Promising technology. The dynamics of expectations in technological developments. University of Twente, Enschede.

Van Lente, H., \& Bakker, S. (2010). Competing expectations: The case of hydrogen storage technologies. Technology Analysis and Strategic Management, 22, 693-709.

Van Lente, H., \& Rip, A. (1998). The rise of membrane technology from Rhetorics to social reality. Social Studies of Science, 28, 221-254.

Van Merkerk, R. O., \& Robinson, D. K. R. (2006). Characterizing the emergence of a technological field: Expectations, agendas and networks in Lab-on-a-chip technologies. Technology Analysis and Strategic Management, 18, 411-428.

Van Rijnsoever, F. J., Farla, J., \& Dijst, M. J. (2009). Consumer car preferences and information search channels. Transportation Research Part D: Transport and Environment, 14, 334-342.

Van Rijnsoever, F. J., Hagen, P., \& Willems, M. (2013). Preferences for alternative fuel vehicles by Dutch local governments. Transportation Research Part D: Transport and Environment, 20, 15-20.

Van Rijnsoever, F. J., Hessels, L. K., \& Vandeberg, R. L. J. (2008). A resource-based view on the interactions of university researchers. Research Policy, 37, 1255-1266.

Van Rijnsoever, F. J., Meeus, M. T. H., \& Donders, R. T. (2012). The effects of economic status and recent experience on innovative behavior under environmental variability: An experimental approach. Research Policy, 41, 833-847.

Wasserman, S., \& Faust, K. (1994). Social network analysis: Methods and applications. Cambridge: Cambridge University Press.

Zambaldi, F., Aranha, F., Lopes, H., \& Politi, R. (2011). Credit granting to small firms: A Brazilian case. Journal of Business Research, 64, 309-315.

Zhang, J. (2010). The problems of using social networks in entrepreneurial resource acquisition. International Small Business Journal, 28, 338-361.

Ziegler, A. (2012). Individual characteristics and stated preferences for alternative energy sources and propulsion technologies in vehicles: A discrete choice analysis for Germany. Transportation Research Part A: Policy and Practice, 46, 1372-1385. 